\title{
ReSEARChArticle
}

\section{Field evaluation of Rot-fix for management of root rot disease of mulberry (Morus sp.)}

\author{
P.M. Pratheesh Kumar
}

\begin{abstract}
SUMMARY
Mulberry is cultivated throughout India as a host plant of silkworm (Bombyx mori L.) reared for commercial production of silk. The quality of silk produced depends largely on the quality of leaf fed to silkworm. Various mulberry diseases limit quality and quantity of silk production affecting the economic return to the farmers. Among these, root rot caused by a group of fungi is a severe threat for mulberry leaf production, especially in southern states of India due to large scale mortality and enormous crop loss. Though many fungi are isolated from the infected root, Fusarium solani is the one frequently found associated with the disease. Chemical control with fungicides is not advisable due the environmental concern and toxicity to the soil and silkworm. Thus, recently a broad spectrum environment friendly formulation viz., Rotfix has been developed by the Central Sericultural Research \& Training Institute, Mysore and recommended after limited on-farm and field trials. However its efficiency has not been evaluated at the farmers' level in large scale. The present study has been conducted to evaluate the effect of Rot-fix in large scale in four southern states of India. The Rot-fix has been applied to the infected plants and their recovery has been studied. There was a high recovery (86.76-91.96\%) of the infected plants after application of Rot-fix. Though the leaf yield was significantly $(\mathrm{P}<0.01)$ lower $(2.48 \%)$ in the recovered plants in first crop, by the second crop the plants were recovered completely and started giving yield the statistically on par with untreated healthy plants. The study therefore recommends the use of Rot-fix in large scale for control of root rot disease of mulberry.
\end{abstract}

Key Words : Field evaluation, Mulberry, Rot-fix, Root rot management

How to cite this article : Pratheesh Kumar, P.M. (2021). Field evaluation of Rot-fix for management of root rot disease of mulberry (Morus sp.). Internat. J. Plant Sci., 16 (2): 135-139, DOI: 10.15740/HAS/IJPS/16.2/135-139, Copyright@ 2021: Hind Agri-Horticultural Society.

Article chronicle : Received : 06.03.2021; Revised : 24.04.2021; Accepted : 07.05.2021 